\title{
The Special Electrophysiological Signs of Inherited Retinal Dystrophies
}

\author{
Elena Prokofyeva, ${ }^{*}, 1,2$ Eric Troeger ${ }^{1}$ and Eberhart Zrenner ${ }^{1}$ \\ ${ }^{1}$ Institute for Ophthalmic Research, Centre for Ophthalmology, University of Tuebingen, Schleichstr, 12-16, D-72076 \\ Tübingen, Germany \\ ${ }^{2}$ Inserm U1018, Centre for Research in Epidemiology \& Population Health (CESP), Epidemiology of Occupational and \\ Social Determinants of Health, Villejuif, France
}

\begin{abstract}
The study aim was to analyze the electrophysiological signs of inherited retinal dystrophies (IRD). Full-field and multifocal (mf) electroretinography (ERG) was analysed in three groups: 21 normal subjects, 21 randomly selected IRD patients, and 21 patients randomly selected from each of eleven IRD groups. As a result, median, 5-95 and 25-75 interquantile intervals of each full-field and mfERG parameter were estimated for each of the above mentioned groups and compared using a Kruskal-Wallis test. Quantitative and qualitative criteria defined in this study will improve the precision of differential diagnosis, the detection of IRD severity, and the efficacy of treatment. The quantitative and qualitative characteristics of ERG values, established in this study, can be further applied to the creation of software that will allow the automatic classification of the recording into a specific disease and degree of severity.
\end{abstract}

Keywords: Electrophysiological signs, early differential diagnosis, visual system, inherited retinal dystrophies.

\section{INTRODUCTION}

The development of new innovative treatments for inherited retinal dystrophies (IRD) is ongoing [1-3], therefore the early identification of patients who can most benefit in the early stages of their disease is of great importance [4]. Disease history, such as typical age of visual symptoms onset and clinical signs, is important for the early identification and differential diagnosis of IRD and can guide clinicians through the diagnostic process [4-6]. Nevertheless, these parameters alone are not sufficient for a final differential diagnosis.

Electrophysiological examination of the visual system has a significant effect on the diagnosis and management of a patients' treatment [7]. Full-field electroretinograms (ERGs) provide a basis for establishing the diagnosis of widespread forms of retinitis pigmentosa in early life, even at a time when fundus abnormalities visible with an ophthalmoscope are minimal or absent [8]. ERG amplitudes are objective measures of retinal function and are useful for accurate diagnosis of the disease, assessment of disease severity [9], follow-up of the course of disease [10], prognosis for visual function [11], and for measurement of responses to treatment, especially when running clinical trials [11]. Multifocal (mf) ERG assesses cone function and provides spatial resolution not readily available in full-field ERG. It is also useful to explain the range of responses obtained from full-field ERG [12].

*Address correspondence to this author at the Institute for Ophthalmic Research, Centre for Ophthalmology, University of Tuebingen, Schleichstr 12-16, D-72076 Tübingen, Germany;

Tel: +49 7071 2984786; Fax: +49 7071 295038;

E-mail: elena.prokofyeva@biomed-engineering.de
Previous studies of full-field and mfERG focused on the estimation of normal values and age-related changes of these values for mfERG [13], on the study of specific changes that are typical for more common IRD types [14-16], or longterm follow-up studies of ERG changes in patients with retinitis pigmentosa [17]. Systematic comparison of full-field and mfERGs in patients with a variety of inherited retinal dystrophies (IRD), as well as with normal ERG values, is important for differential diagnosis at early diseases stages, as well as for patient counseling, prognosis, and disease progression and treatment outcomes assessment. Despite its high importance, to the best of our knowledge there are no studies that comprehensively compare such a wide variety of inherited retinal dystrophies. Therefore, the aim of this study is to analyze and compare the special electrophysiological signs (quantitative characteristics of full-field and mfERG) and define qualitative criteria for full-field and mfERG in IRD.

\section{MATERIALS AND METHODS}

\section{Study Population and Patient Selection}

Patients with the following diagnoses were selected for the study: retinitis pigmentosa (RP), Stargardt disease (STD), central areolar choroidal dystrophy (CACD), cone dystrophies (CD), cone-rod dystrophies (CRD), vitelliformis (Best's disease), pseudovitelliformis macular dystrophy (MD), pattern MD, Bardet-Biedl syndrome (BBD), Usher syndrome I (USH I) and II (USH II), choroideremia (CHRD), and Leber congenital amaurosis (LCA). Normal subjects had no medical history of eye disease and did not show any pathological signs in best corrected visual acuity, Goldmann or semiautomatic kinetic perimetry, color testing (Panel D15 test), examination of the anterior segment, funduscopy, and Ganzfeld ERG and mfERG according to current ISCEV protocols. Patients with uncertain 
diagnosis and those who did not undergo electrophysiological examination were excluded from the study. Final diagnosis was established by a team of senior resident ophthalmologists at the University Eye Hospital, Tuebingen. It was based on a comprehensive analysis of the disease history, clinical data including best corrected visual acuity, the examination of anterior segment and fundoscopy, visual field data from Goldmann or semiautomatic kinetic perimetery, color testing (Panel D15 test), full-field ERG and mfERG. The geographic distribution of patients in the study population was analyzed by accounting for the first number in the postal code, which divides Germany into ten regions.

A random subsample of patients with IRD and subjects with normal ophthalmological findings was selected to evaluate the distribution of full-field and mfERG values in normal subjects, in the IRD population overall, and in each of the IRD subgroups. On the basis of these results qualitative criteria for full-field and mfERG were formulated.

The study aimed to estimate typical values for the amplitudes and implicit times in normal subjects, in the IRD population as a whole, and in each of the disease groups. The disease duration at first visit was calculated for each of the IRD types, and represented the difference between the age at which patient first visited the eye hospital and the age when a patient first experienced disease symptoms. The median amplitudes and implicit times for each of the waves with 25th and 75th and 5th and 95th quantiles were calculated for full-field ERG, as well as for mfERG. The comparison of the parameters' medians between different IRD types was performed using box-plots [18] and a Kruskal-Wallis test [19]. For this purpose 21 patients were randomly selected from the population, including the whole IRD study population $(n=544)$, as described by us elsewhere [4] (for estimation of the median of IRD population as a whole and definition of the criteria for the qualitative data assessment), as well as from subsets including each above mentioned IRD (for calculation of the median values for each of IRD and for the median comparison). 21 patients with normal ophthalmological findings were selected as a reference group. The sample size of 21 patients/controls for the random selection was chosen based on the fact that a sample size equal to 21 patients/controls enables us to estimate the median with a very low variance, whereas increasing the sample size over 21 will not substantially influence the variance of the median [20].

Response parameters of the first order kernel of the mfERG were analysed by grouping the responses into five concentric rings and averaging them [21]. The median and $5^{\text {th }}$ and $95^{\text {th }}$ quantiles of the amplitudes and implicit times in Ring 1 (RI), Ring 2 (RII), Ring 3 (RIII), and Ring 4 (RIV) were calculated for the reference group and a random sample from the IRD study population. mfERG parameters were compared between the different types of IRD and normal subjects. Implicit times were also averaged for each of the concentric rings and further compared between different IRD types and subjects with normal ophthalmological findings.

Criteria for the qualitative evaluation of mfERGs in IRD patients were defined. It was proposed that the amplitude ranging from the maximum of IRD population values to the $25^{\text {th }}$ quantile of the IRD population were considered moderately reduced. The amplitudes lower than the $25^{\text {th }}$ quantile and higher than the minimum amplitude for the IRD population were considered to be severely reduced. Implicit times that were higher than the maximal normal value and lower than the $75^{\text {th }}$ quantile of IRD population values were characterized as moderately prolonged. Implicit times that exceeded the $75^{\text {th }}$ quantile and were equal to or exceeded the maximum implicit time values of the IRD population median were characterized as severely prolonged. A Kruskal-Wallis test $\left(\mathrm{Chi}^{2}\right.$-test for more than 2 groups) was used for the comparison of full-field and mfERG amplitudes and implicit times of IRD subgroups and with subjects with normal ophthalmological finding.

\section{Data Collection}

Electrophysiological examination included full-field electroretinography and multifocal electroretinography (mfERG). Full-field electroretinograms were recorded according to the ISCEV standard [22] with an espion $E^{2}$ system and ColorDome Ganzfeld stimulator (Diagnosys UK Ltd, Cambridge, UK) using DTL electrodes. A stimulus of 0.007 $\mathrm{cds} / \mathrm{m}^{2}$ was used for recording dark adopted rod b-wave. White flashes at a standard flash intensity of $2.25 \mathrm{cds} / \mathrm{m}^{2}$ were used for maximum a and $b$-waves as well as for the oscillatory potentials recordings. L-cone single red flashes $(650 \mathrm{~nm})$ at a flash intensity of $2.25 \mathrm{cds} / \mathrm{m}^{2}$ in a light adapted state $\left(34 \mathrm{~cd} / \mathrm{m}^{2}\right)$ were used for photopic cone signals recording. mfERG was performed according to the method described by Sutter and Tran [23] using the VERIS system with luminance of the screen elements $100 \mathrm{~cd} / \mathrm{m}^{2}$ in the lighted state and $<1 \mathrm{~cd} / \mathrm{m}^{2}$ in the dark state (EDI, San Francisco, CA, USA).

\section{Data Management}

Patient data was obtained by senior ophthalmologists specialized in IRD and stored electronically in a generic patient registry (Ophthabase). The structure and technical details of Ophthabase design were described by us earlier [24,25]. Electronically stored data was entirely pseudonymized. Access to patient data was limited to the researchers taking part in the study. Collected data included general information such as age, sex, postal code, history of the disease (age of the typical symptoms onset and age at first diagnosis), clinical data (best corrected visual acuity and perimetry data), and technical data (full-field and mfERG) which were analyzed and discussed by us in detail elsewhere [4]. The information obtained during the patients' first visit to the eye hospital.

All persons involved in the study or their legal guardians agreed to participate. The study was designed in accordance with the tenets of the 1964 Declaration of Helsinki. The study protocol was approved by the Ethics Commission of the Medical Faculty, Eberhard-Karls University, Tuebingen, Germany. All information in the study was handled with a special guarantee of security.

\section{RESULTS}

\section{Quantitative Assessment of the Full-Field and mfERG Parameters and their Comparison Between a Variety of IRD and Normal Values}

Disease duration at first visit was considered as one of the confounders that can potentially influence the comparison of full-field and mfERG parameters in a variety of IRD. Therefore, the data on disease duration was analyzed 
for each IRD and compared using a Kruskal-Wallis test. The disease duration was not significantly different between the IRD types $(p=0.23)$ (Fig. 1), which justifies the comparison of full-field and mfERG parameters between the selected IRD patients. The disease duration at first visit is shown in Table 1.

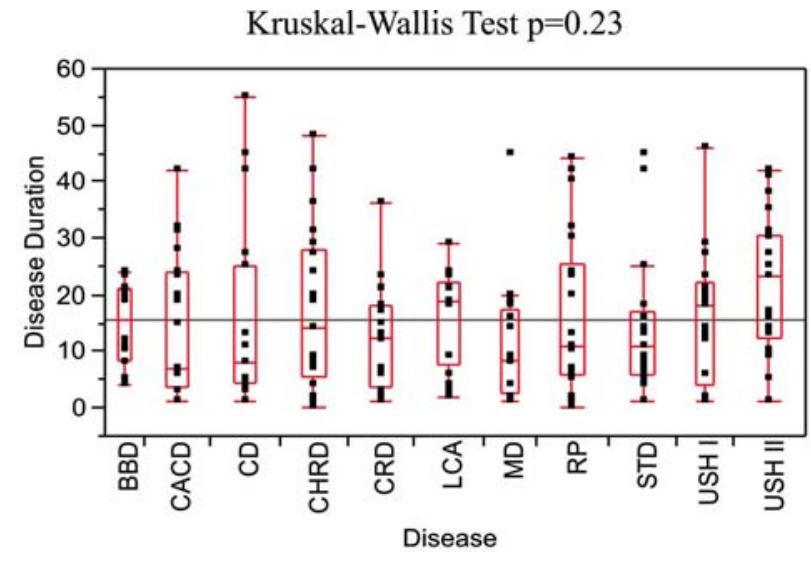

Fig. (1). Box-plots of disease duration at the first visit to the eye hospital in a variety of IRD.

Table 1. Disease Duration at First Visit in Inherited Retinal Dystrophies

\begin{tabular}{|c|c|c|c|}
\hline Disease & Median & 25th Quantile & 75th Quantile \\
\hline \hline USH I & 18 & 4 & 22 \\
\hline USH II & 23 & 12,25 & 30,25 \\
\hline STD & 11 & 6 & 17 \\
\hline RP & 11 & 5,75 & 25,5 \\
\hline MD & 8,5 & 2,5 & 17,5 \\
\hline CRD & 12,5 & 3,75 & 18 \\
\hline CD & 8 & 4,5 & 25 \\
\hline CHRD & 14 & 5,5 & 28 \\
\hline CACD & 7 & 3,75 & 23,75 \\
\hline BBD & 15,5 & 8,5 & 21 \\
\hline LCA & 19 & 7,5 & 22 \\
\hline
\end{tabular}

The majority of the patients were from the South-West (n = 252), where the University Eye Hospital is located. Nevertheless, patients with IRD were forwarded to the hospital from all over Germany.

Median values for full-field and mfERG parameters in normal subjects and randomly selected IRD patients were calculated and used for the definition of the qualitative assessment criteria for evaluation of the full-field and mfERG parameters. Median, minimal, and maximum values, $5^{\text {th }}, 25^{\text {th }}, 75^{\text {th }}, 95^{\text {th }}$ quantiles of full-field ERG for normal subjects and a random selection of IRD patients were calculated and are shown in Table 2. mfERG is shown in Table 3.
Comparison of Median Values of Full-Field ERG Amplitudes in a Variety of IRD Types

Photopic a-wave was non-detectable in USH I and USH II, and BBD patients and was the most reduced in patients with CRD, CACD, CHRD $(\mathrm{p}=0.0001) \quad$ (Fig. 2a). Interestingly, the photopic a-wave was almost equally reduced in patients with RP and CD, whereas patients with STD and MD had amplitude close to the normal range. BBD, CHRD, CRD and RP patients had the most reduced amplitudes of the maximum b-wave (p=0.0001) (Fig. 2b). A similar trend was observed for the amplitude of the maximum a-wave, which was most reduced in patients with BBD, CHRD, CRD, RP, and CACD ( $\mathrm{p}=0.0001)$ (Fig. 2c). Oscillatory potentials were non-detectable in BBD, and USH I and II patients. Patients with CHRD, RP, CRD, and CACD had on average lower median oscillatory potentials amplitudes in comparison to other IRD types, $(p=0.0001)$ (Fig. 2d). Rod b wave amplitude was non-detectable in $\mathrm{BBD}$, or USH I and II types and was significantly reduced in patients with CHRD, CRD, CACD, RP and STD ( $\mathrm{p}=0.0039)$ (Fig. 2e). $30 \mathrm{~Hz}$ flicker were significantly more reduced in patients with USH I, RP, BBD, CHRD, CRD, and CD in comparison to other IRD types $(p=0,0001)$ (Fig. 2f). USH I and CHRD had the most reduced photopic b-wave amplitude, with low variance, whereas patients with RP, CRD and $C D$ had slightly less reduced amplitudes with higher variance $(\mathrm{p}=0,0001)$. Patients with CACD, STD, and MD had amplitude close to normative values (Fig. 2g). A detailed comparison of the amplitudes in a variety of IRD is shown using box-plots in Fig. (2). The comparison of amplitudes between different IRDs types and with normal parameters using a Kruskal-Wallis test is shown in Table 4.

\section{Comparison of the Median Values of Full-Field ERG Implicit Time in a Variety of IRD Types}

Implicit times were observed to be less variable in comparison with amplitude. The implicit time of photopic awave was significantly more prolonged in patients with RP, CRD, and CHRD ( $p=0.0001$ ) (Fig. 3a), whereas photopic bwave implicit time was observed to be in a normal range in patients with MD and was significantly more prolonged in patients with BBD, RP, CRD, CHRD, and USH I in comparison to other IRD types $(p=0.0001)$ (Fig. 3g). The difference between the implicit times of the maximum bwaves was not significant $(\mathrm{p}=0.221)$ (Fig. 3b). Maximum awave implicit time was close to normal in all the observed IRD types. A slight prolongation was noted in CRD, STD, $\mathrm{CD}, \mathrm{RP}$, and CHRD, but no statistical significant difference was found $(\mathrm{p}=0.4392)$ (Fig. 3c). Oscillatory potentials implicit times differ just slightly between different IRD types, were not recordable in BBD, USH I, USH II patients, and were close to normal in patients with $C D, C R D$, and RP $(\mathrm{p}=0.0001)$ (Fig. 3d). The implicit time of the rod $b$-wave was within the normal range in patients in CD and CHRD, and slightly prolonged in CACD, STD, RP, MD, and CRD $(\mathrm{p}=0.0097)$ (Fig. 3e). $30 \mathrm{~Hz}$ flicker implicit time was significantly more prolonged in patients with BBD, CHRD, $\mathrm{CRD}, \mathrm{RP}$, and $\mathrm{CD}$ in comparison to other IRD $(\mathrm{p}=0.0001)$ (Fig. 3f). The comparison of implicit times between different 
Table 2. The Quantitative Characteristics of Full-Field ERG Parameters in Subjects with Normal Ophthalmological Findings, and in the IRD Study Population

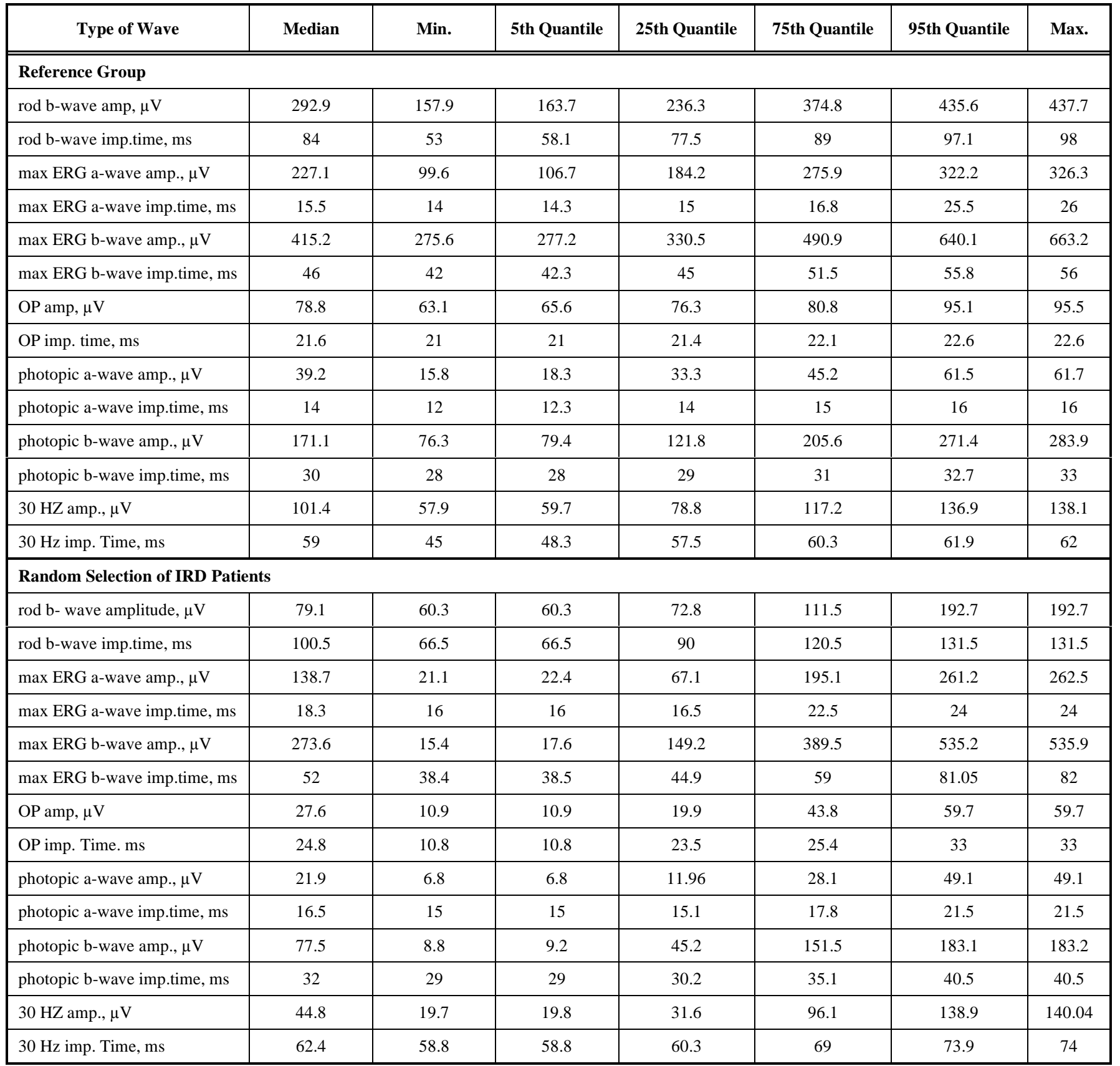

IRDs types and with normal parameters, using a KruskalWallis test is shown in Table $\mathbf{5}$.

\section{Comparison of Median mfERG Amplitudes in a Variety of IRD}

The amplitude in the first ring (RI) of the mfERG was significantly more reduced in patients with USH I, STD, USH II, CACD, CD, and CHRD than in those with CRD, $\mathrm{RP}$, and MD $(\mathrm{p}=0.0001)$, which were closer to the lower limit of the normal values (Fig. 4a). The amplitude of the second ring (RII) was in the normal range in patients with $\mathrm{MD}$, and significantly reduced in CD, CHRD, RP, CRD, and USH II. RP RII amplitude was quite variable and the maximum of RII amplitudes in RP reached the minimum normal value. A similar trend was observed in CD and CRD patients. These differences were statistically significant $(\mathrm{p}=0.0001)$ (Fig. 4b). The third ring (RIII) amplitude was significantly more reduced in CRD, RP, CHRD, and USH I in comparison with CD, USH II, CACD, STD, and MD $(\mathrm{p}=0.0001)$ (Fig. 4c). The amplitude of RIII in MD was detected to be in the normal range. The high variation of STD and CD resulted in their maximum values being in the normal range. The amplitude of the fourth ring (RIV) was significantly more reduced in USH I, USH II, RP, CRD, CHRD, and CACD ( $\mathrm{p}=0.0001)$ (Fig. 4d). The patients with $\mathrm{CD}$, and STD had high variation in their amplitude values and therefore the values of these patients were on average closer to normal and had a more moderate reduction in 
Table 3. The Quantitative Characteristics of mfERG Parameters in the Reference Group, and in the IRD Population

\begin{tabular}{|c|c|c|c|c|c|c|c|}
\hline mfERG Parameter & Median & Min. & 5th Quantile & 25th Quantile & 75th Quantile & 95th Quantile & Max. \\
\hline \multicolumn{8}{|l|}{ Reference Group } \\
\hline RII Amplitude, nV & 34.5 & 14.2 & 14.7 & 24.6 & 43.95 & 53.3 & 55.4 \\
\hline RIII Amplitude, nV & 20.2 & 9.6 & 9.9 & 16.5 & 26.3 & 29.5 & 29.8 \\
\hline RIV Amplitude, nV & 14 & 7.4 & 7.5 & 10.3 & 19 & 27.1 & 28.8 \\
\hline RI Implicit time, ms & 29.2 & 7.9 & 13.8 & 29.1 & 30 & 30.8 & 30.8 \\
\hline RII Implicit time, ms & 29.2 & 26.6 & 26.6 & 28.3 & 30 & 30 & 30 \\
\hline RIII Implicit time, ms & 28.3 & 25.8 & 26.04 & 27.9 & 29.2 & 29.8 & 30 \\
\hline RIV Implicit time, ms & 29.2 & 25.7 & 25.97 & 28.2 & 29.2 & 31.99 & 32.5 \\
\hline RV Implicit time, $\mathrm{ms}$ & 29.2 & 26.6 & 26.6 & 28.3 & 30 & 35.5 & 37.5 \\
\hline RIAmplitude, nV & 12.9 & 5.4 & 5.4 & 9.9 & 22.7 & 34 & 34 \\
\hline RII Amplitude, nV & 8.9 & 2.1 & 2.1 & 5.1 & 12.2 & 15.3 & 15.3 \\
\hline RIII Amplitude, nV & 7.4 & 1.5 & 1.5 & 2.8 & 11.05 & 18.9 & 18.9 \\
\hline RIV Amplitudel, nV & 6.3 & 1.4 & 1.4 & 2.2 & 10.3 & 18.5 & 18.5 \\
\hline RV Amplitude, nV & 6.6 & 1.4 & 1.4 & 2.5 & 9.95 & 15.3 & 15.3 \\
\hline RI Implicit time, ms & 30 & 25.7 & 25.7 & 29.2 & 32.9 & 38.3 & 38.3 \\
\hline RII Implicit time, ms & 31.2 & 27.4 & 27.4 & 28.95 & 34.6 & 44.1 & 44.1 \\
\hline RIII Implicit time, ms & 31.3 & 27.4 & 27.4 & 29.1 & 35.8 & 42.5 & 42.5 \\
\hline RIV Implicit time, ms & 33.8 & 27.4 & 27.4 & 29.8 & 36.2 & 45 & 45 \\
\hline
\end{tabular}

comparison with other IRD types. The amplitude of the fifth ring was characterized by a significant amplitude reduction in USH II, CHRD, CRD, RP, and CD. CACD patients had a mild RV amplitude reduction, whereas STD and MD had RV amplitudes within a normal range $(\mathrm{p}=0.0001)$ (Fig. 4e). The comparison of mfERG amplitudes between different types of IRD and with normal values is shown in Table 5.

\section{Comparison of mfERG Implicit Time in a Variety of IRD Types}

mfERG implicit times were characterized by less variability than mfERG amplitudes (Fig. $\mathbf{4 f - j}$ ). Implicit times of the first ring (RI) were in the range of normal values in USH I and USH II. Patients with CHRD, and CACD had a more prolonged implicit time in RI in comparison with patients who were diagnosed with $\mathrm{CRD}, \mathrm{MD}, \mathrm{RP}, \mathrm{CD}$ and STD ( $p=0.0032)$ (Fig. 4f). Implicit amplitude of the second mfERG ring was close to normal in USH II and USH I patients. It was observed that CACD had significantly more prolonged implicit time than other IRD types $(p=0.0382)$ (Fig. 4g). Implicit time of the third and the fourth rings showed quite a similar trend when comparing between different IRD types: USH I implicit times were significantly less prolonged than those in USH II in both RIII ( $p=0.0001)$ (Fig. 4h) and in RIV ( $\mathrm{p}=0.0001$ ) (Fig. 4i). Overall, ring 3 was characterized by significantly more prolonged implicit times in patients with USH II, CACD, CRD, CHRD and
STD $(p=0.0001)$ in comparison with other IRD types (Fig. 4h). Ring 4 implicit times were significantly more prolonged in USH II, CRD, CACD, and CHRD ( $\mathrm{p}=0.0001)$ (Fig. 4i). Implicit times in ring 5 were significantly more prolonged in USH II, CRD, and CHRD in comparison with other IRD types $(\mathrm{p}=0.0001)$. USH I had no signal detectable in ring 5 (Fig. 4j). The comparison of mfERG implicit times between different types of IRD and with normal values is shown in Table $\mathbf{5}$.

\section{DISCUSSION}

This study is, to the best of our knowledge, the only study with evaluation of both full-field and mfERG in such a wide variety of IRD. Previous publications focused on the detection of normative values for full-field ERG parameters as well as values for single IRD types (CD, CRD, and STD) [26], the estimation of normal values for mfERG [27], or on the differential diagnosis of the subtypes of frequent IRD types such as differentiation between Usher syndrome subtypes [14]. Despite the very high value of this research, the comparison of the electrophysiological data between normal subjects and different IRD types as well as between IRD types is still largely lacking. Cases of IRD sometimes are difficult to classify due to large variations of electrophysiological parameters within a given disease category, therefore it is important to investigate the amount of such variations. For example, cone ERGs are not always 
Table 4. Comparison of Full-Field ERG Values Between Different Types of IRD and with Normal Values

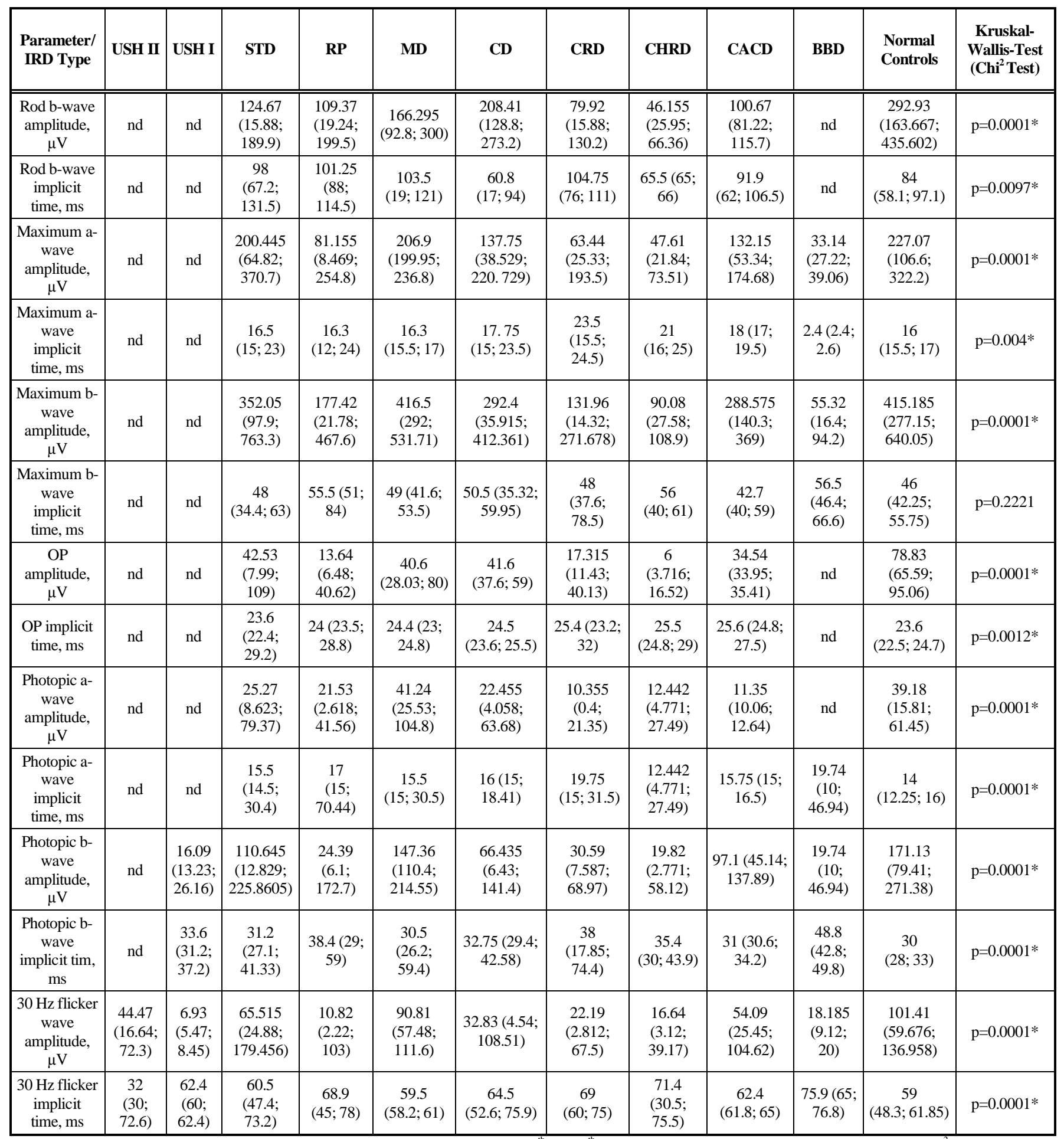

nd- not detectable; ${ }^{*}$-indicates that the difference was found to be statistically significant; $5^{\text {th }}$ and $95^{\text {th }}$ quantiles are indicated in brackets; Kruskal-Wallis test (Chi ${ }^{2}$-test for more than 2 groups) was used for the comparison of IRD subgroups and with subjects with normal ophthalmological finding.

very robust in Stargardt cases, which are often hard to differentiate from cone dystrophy. Consequently, knowledge about such variations is valuable, especially as there are large variations depending on the stage of disease. Very seldom can a firm clinical diagnosis be based on a single electrophysiological parameter, therefore possible deviations of each of the parameters from their expectations is worthwhile to explore. Furthermore, there are no generally accepted qualitative and quantitative criteria for the reduction in electrophysiological parameters, which are necessary for the assessment of disease severity and are required to better communicate of test results to patients.

Van Lith established that qualitative descriptions or labels of ERG wave-forms are less desirable to use in a clinical practice than quantitative determinations [28]. He 


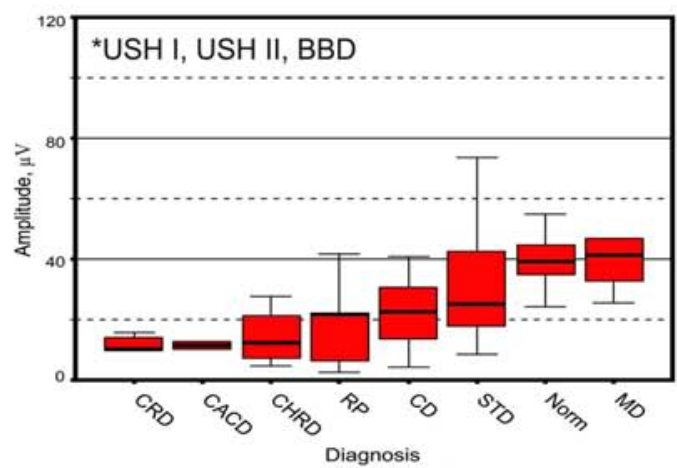

Figure 2a. Box-plots of photopic a-wave amplitude in different IRD types.

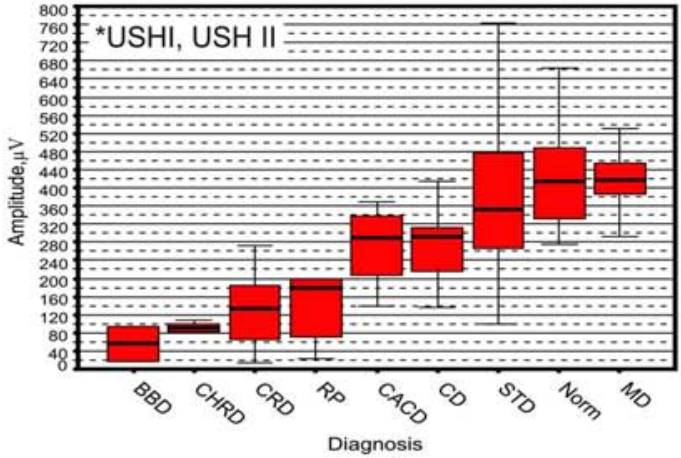

Figure 2b. Box-plots of maximum b-wave amplitude in different IRD types.

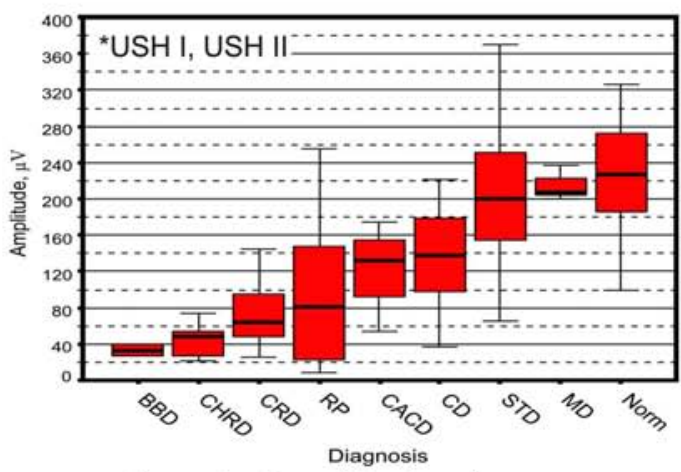

Figure 2c. Box plots of maximum a-wave amplitude in different types of IRD.

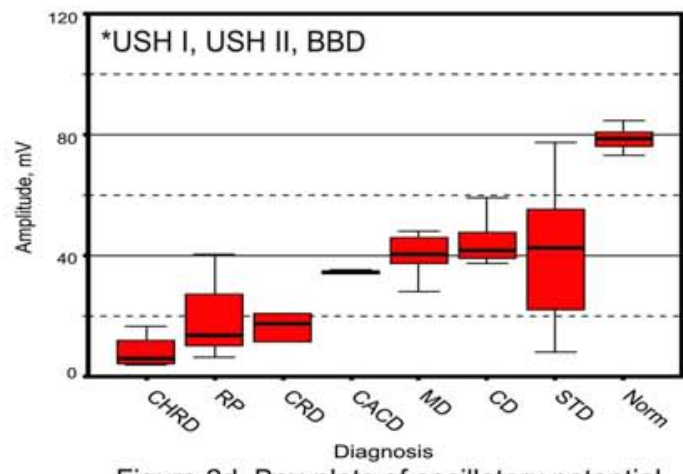

Figure 2d. Box-plots of oscillatory potential amplitude in different IRD types.

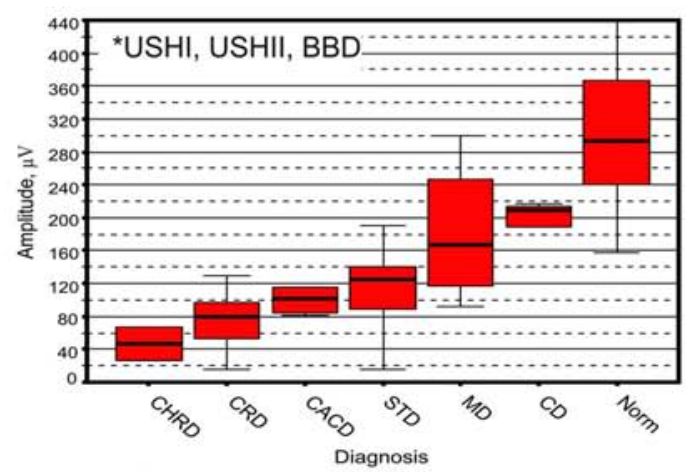

Figure 2e. Box-plots of rod b-wave amplitude in different types of IRD.

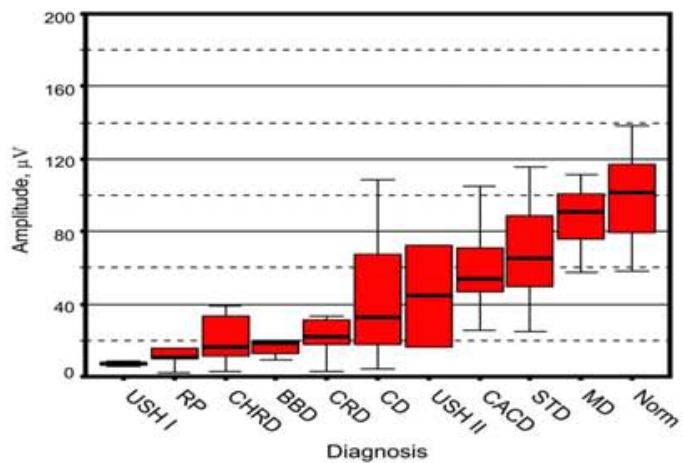

Figure 2f. Box-plots of $30 \mathrm{~Hz}$ flicker amplitude in different types of IRD.

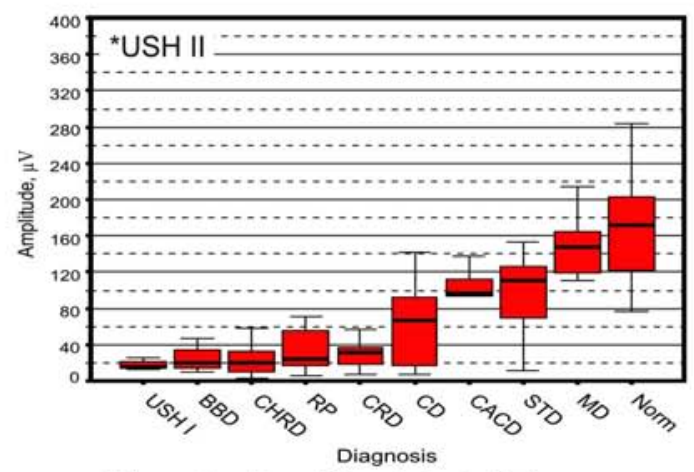

Figure 2g. Box-plots of photopic b-wave amplitude in different IRD types.

*- patients with non-detectable full-field ERG

Fig. (2). Box-plots of full-field ERG amplitudes in a variety of IRD. 


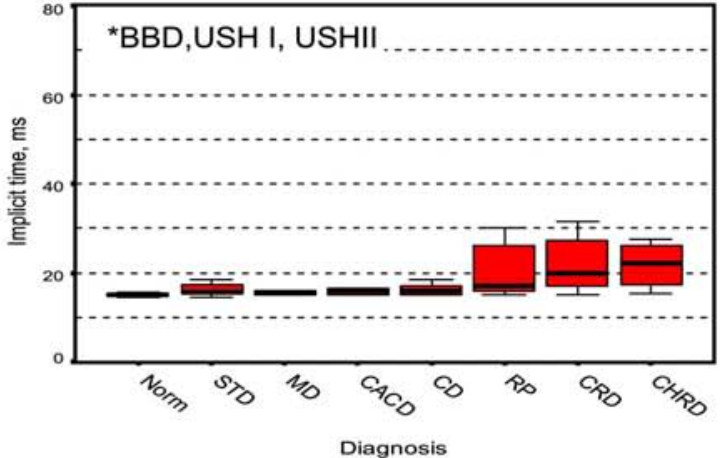

Figure 3a. Box-plots of photopic a-wave implicit time in different IRD types.

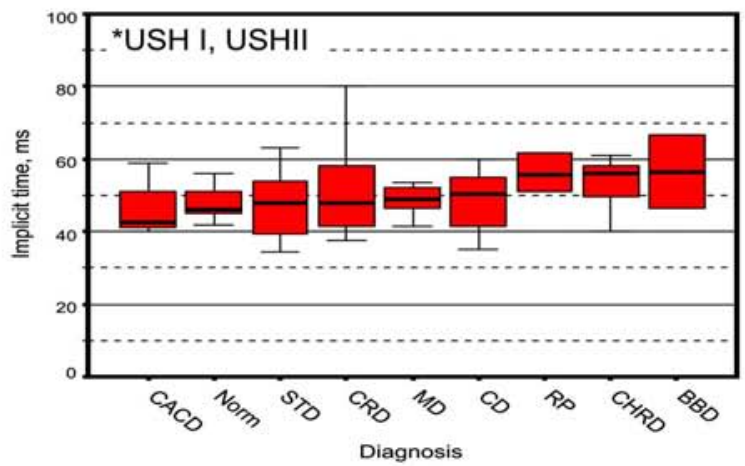

Figure 3b. Box-plots of maximum b-wave implicit time in different IRD types.

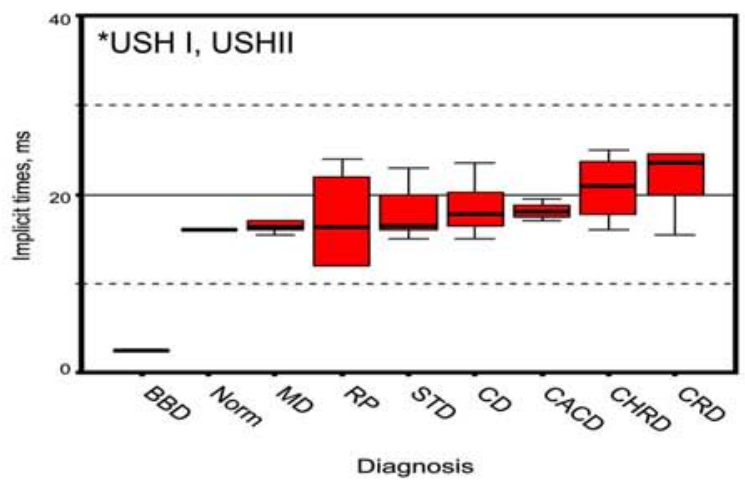

Figure 3c. Box-plots of maximum a-wave implicit time in different IRD types.

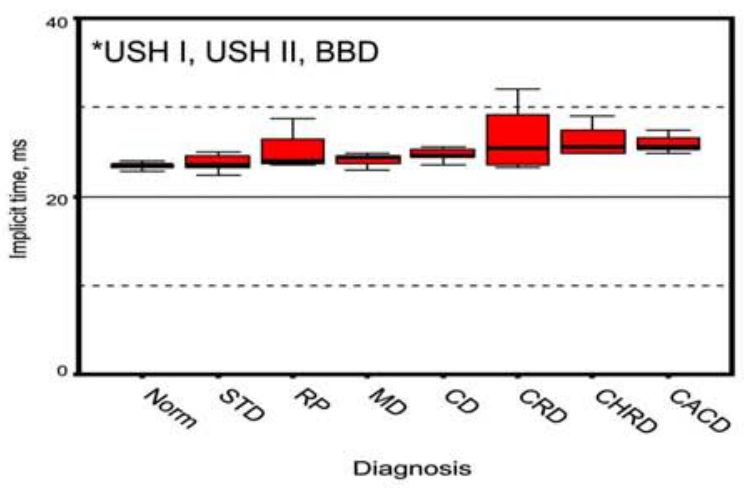

Figure 3d. Box-plots of oscillatory potentials implicit time in different IRD types.

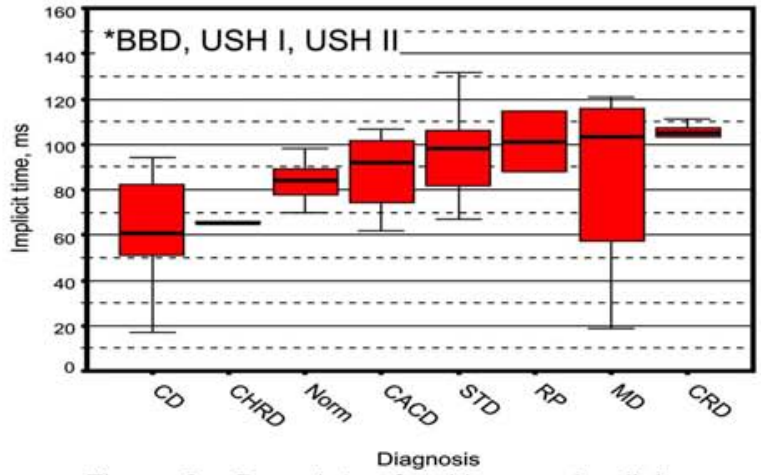

Figure 3e. Box-plots of rod b-wave implicit time in different IRD types.

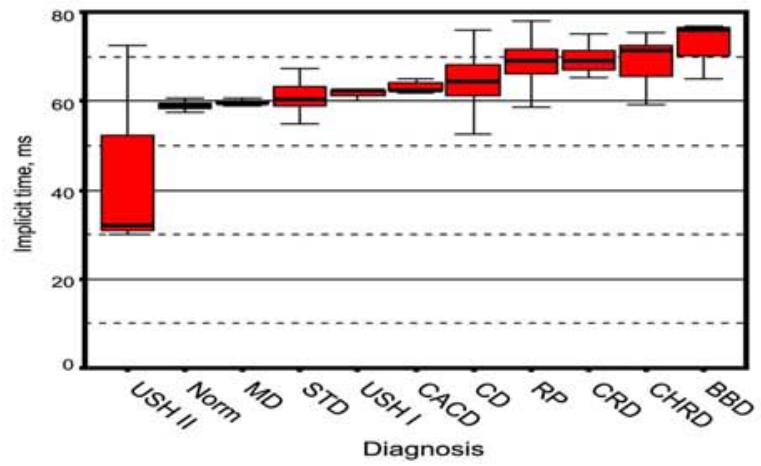

Figure 3f. Box-plots of $30 \mathrm{~Hz}$ flicker implicit time in different IRD types.

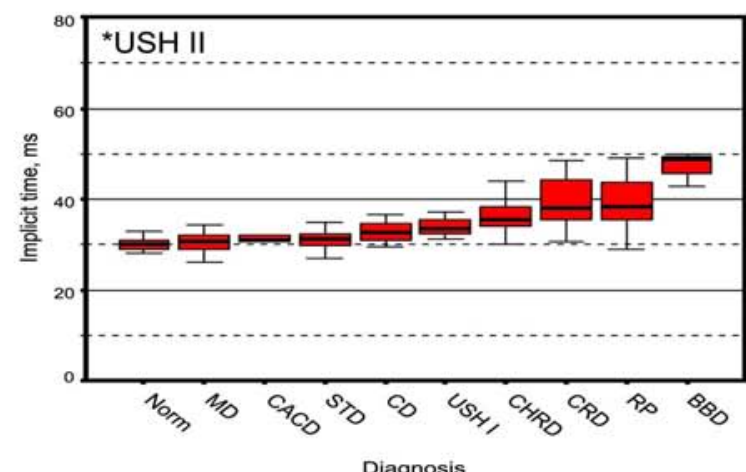

Figure 3g. Box-plots of photopic b-wave implicit time in different types of IRD.

*-patients with non-detectable full-field ERG

Fig. (3). Box-plots of full-field ERG implicit times in a variety of IRD. 
proposed to determine the lower limit by obtaining a standard deviation value of 2 in reference to the mode, and then the reduction of amplitude was expressed in the percentage of the mode and the lower limit. Nevertheless, one could argue that standard deviation would not be most optimal to use in order to characterize non-normally distributed ERG data. Therefore in this study non-parametric statistics (median and quantiles) were used to describe the ERG data. In addition, Fishman and coauthors noted that describing an ERG result as solely "subnormal" is inexact and in need of quantitative documentation [29]. Despite this fact, such qualitative descriptions are still quite often used to describe ERG data along with quantitative data. Therefore in this study we formulated the approach of using both quantitative and qualitative characteristics for full-field and mfERGs data. Indeed, the interrelated use of qualitative and quantitative measures will assist in the comparison of electrophysiological data between disease groups and will increase the efficacy of communication with the patient. Moreover, quantitative and qualitative characteristics of ERG values can be further applied to the creation of software that will allow the automatic classification of the recording into a specific disease and degree of severity.

As a result of this study we were able to estimate the normal parameters of full-field and mfERG, which were used as a reference for the current study and could be potentially helpful in future studies. We also calculated the median and 25-75 and 5-95 quantiles for the random sample of IRD population, which enabled us to define the criteria for qualitative assessment of full-field and mfERGs. Importantly, as a result of this study we calculated the median and 5-95 quantiles of each full-field ERG and mfERG parameter for each IRD type. Furthermore, medians of the identical parameters of full-field and mfERGs were compared between IRD types using a Kruskal-Wallis test. Observed differences can be used as guidelines for differential diagnosis of IRD. The qualitative characteristics of full-field and mfERG amplitudes were considered as moderately reduced if the amplitudes ranged from the maximum of IRD population values to the $25^{\text {th }}$ quantile of the IRD population, and severely reduced if amplitudes were lower than the $25^{\text {th }}$ quantile and higher than the minimum amplitude of the IRD population. Implicit times that were higher than maximal normal values and lower than the $75^{\text {th }}$ quantile of IRD population values were characterized as moderately prolonged. Implicit times exceeding the $75^{\text {th }}$ quantile and equal or exceeding the maximal implicit time values of IRD population median were categorized as severely prolonged.

We observed that patients with RP, despite their predominant affection of the rod system, also often had substantially decreased amplitudes and prolonged implicit times in photopic ERG. On the other hand CRD, besides the decrease of photopic amplitudes, were characterized by decreased scotopic amplitudes as well as prolonged implicit times. Similar findings were described by Fishman et al. [30] and can be interpreted in CRD as a sign of the beginning of cone involvement in the first stage and rod involvement in the second stage. Furthermore, our study also showed that USH I has significantly less prolonged mfERG implicit times than USH II, which corresponds to previous findings
[14]. Interestingly, the described differences were mostly observed in peripheral mfERG rings, whereas in central rings these differences were not as obvious. MD was represented by a normal full-field ERG, which differentiates it from other IRD and conforms to the results of other studies [31]. The majority of patients with STD had scotopic and photopic full-field ERG within a normal range with moderately reduced amplitudes and moderately prolonged implicit times, which corresponds to previous findings [32]. CACD was characterized by normal or moderately reduced amplitudes and normal or moderately prolonged implicit time in both scotopic and photopic conditions, which corresponds to previous findings $[33,34]$.

This study has some limitations. The analysis was limited to the information obtained during the patients' first visit to the eye hospital. The study had a retrospective crosssectional design, which increases the chance of selection bias. Random selection of patients was used in order to avoid this possibility. Nevertheless, the study was done on a sufficiently large sample size of a wide variety of rare IRD. Patients with different IRD types were not significantly different in respect to the disease duration, which rules out a potentially significant confounding factor and justifies the comparison between patients in this sample. The results of the study are representative of the IRD population in the south-west of Germany, from where the majority of patients came, but the comparatively small sample size of patients from other regions of Germany indicates that results of this study may not be generalizable to the IRD population in Germany as a whole. The data was obtained by senior research ophthalmologists using an elaborated standardized approach, which complies with clinical guidelines and ISCEV standard protocols. Therefore the results of the study can be considered reliable.

Overall, this study lead to the estimation of quantitative $\mathrm{mf}$ and full-field ERG criteria for normal subjects and a variety of IRD, which enables us to detect the presence of IRD and to differentiate between different IRD types. Furthermore, it resulted in the formulation of qualitative criteria that will help to estimate the severity IRD. These criteria will be of high value for the estimation of prognosis as well as for planning rehabilitation and/or treatment measures. It is often very difficult to differentiate between various types of IRD, especially in later stages of the disease. The interrelated use of qualitative and quantitative measures can provide crucial help when comparing electrophysiological data between disease groups and will thereby increase the efficacy of communication with the patient. Moreover, quantitative and qualitative characteristics of ERG values can be further applied to the creation of software that will help with diagnosing specific disease type and degree of severity. This appears particularly important for providing guidelines for non-specialized ophthalmologists, as expert ophthalmologists specialized in such a wide range of IRD are in short supply.

We propose an algorithm where the results of full-field and $\mathrm{mf}$ ERG are compared against normal measures and measures of the IRD population in order to identify the presence of any IRD. Subsequently, each amplitude and implicit time can be compared to corresponding parameters 


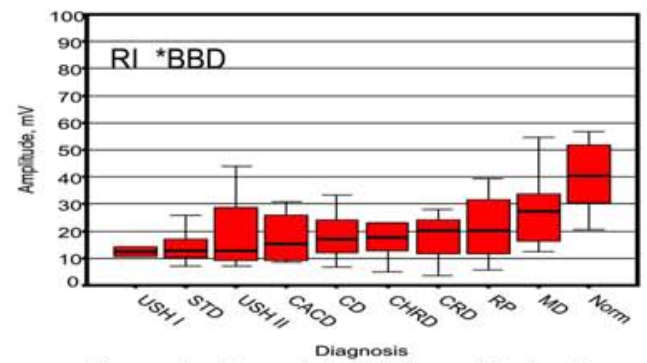

Figure 4a. Box-plots of RI amplitude of mfERG in different IRD types.

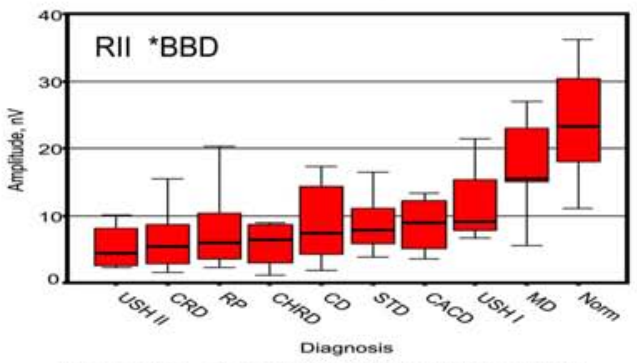

Figure 4b. Box-plots of RII amplitude of mfERG in different IRD types.

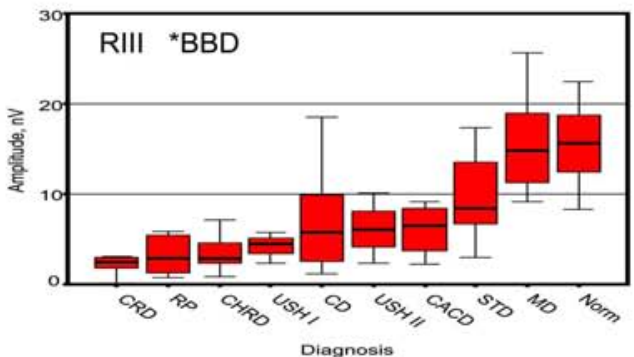

Figure 4c. Box-plots of RIII amplitude of mfERG in different IRD types.

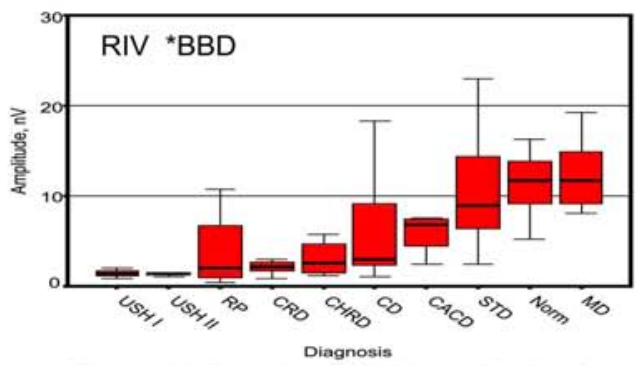

Figure 4d. Box-plots of RIV amplitude of mfERG in different IRD types.

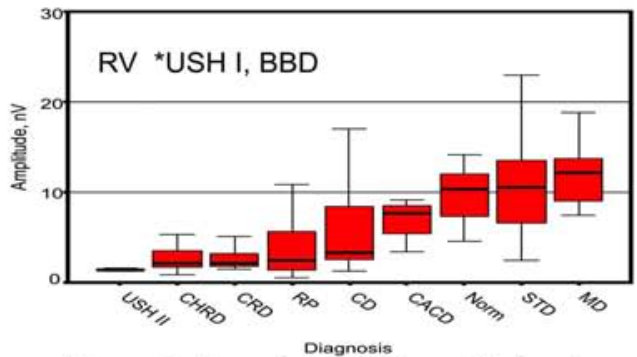

Figure $4 \mathrm{e}$. Box-plots of RV amplitude of mfERG in different IRD types.

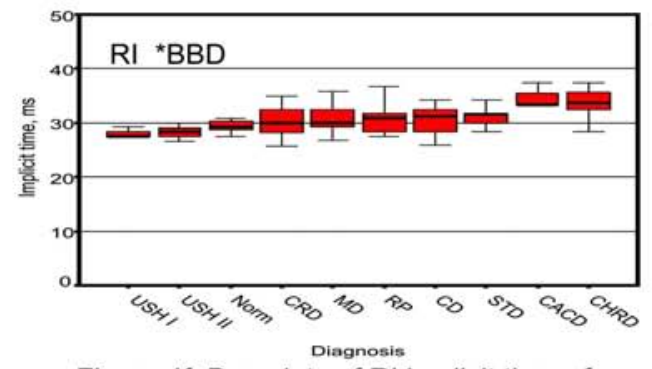

Figure 4f. Box-plots of RI implicit time of mfERG in different IRD types.

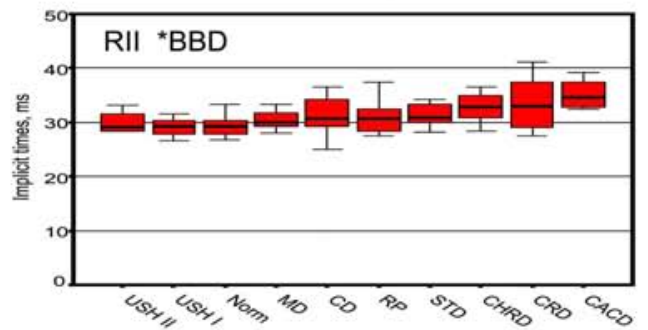

Diagnosis

Figure $4 \mathrm{~g}$. Box-plots of RII implicit time of mfERG in different IRD types.

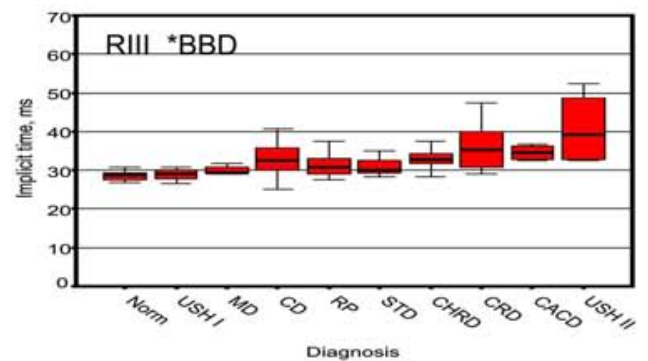

Figure 4h. Box-plots of RIII implicit time of mfERG in different IRD types.

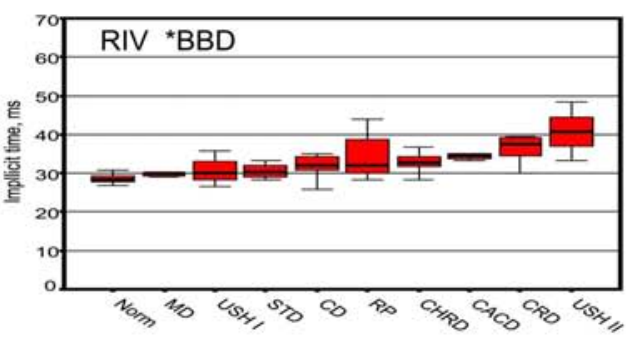

Diagnosis

Figure 4i. Box-plots of RIV implicit time of mfERG in different IRD types.

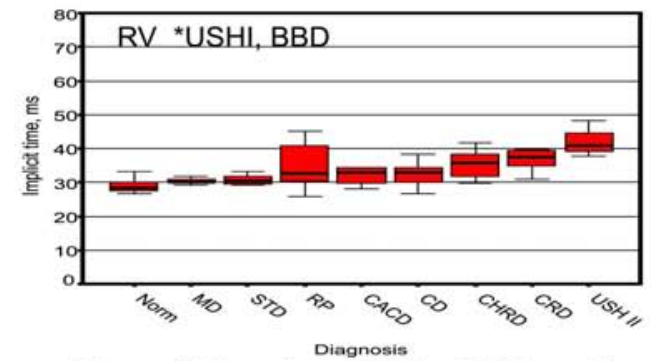

Figure 4j. Box-plots of RV implicit time of mfERG in different IRD types.

\section{"-patients with non-recordable mfERG}

Fig. (4). Box-plots of mfERG amplitudes and implicit times in a variety of IRD. 
Table 5. Comparison of mfERG Values Between Different Types of IRD and Normal Values

\begin{tabular}{|c|c|c|c|c|c|c|c|c|c|c|c|c|}
\hline $\begin{array}{l}\text { Parameters/ } \\
\text { IRD Types }\end{array}$ & USH II & USH I & STD & $\mathbf{R P}$ & MD & CD & CRD & CHRD & CACD & BBD & $\begin{array}{l}\text { Normal } \\
\text { Controls }\end{array}$ & $\begin{array}{c}\text { Kruskal- } \\
\text { Wallis } \\
\text {-Test } \\
\text { (Chi' }{ }^{2} \text { Test) }\end{array}$ \\
\hline $\begin{array}{l}\text { RI Amplitude, } \\
\text { nV }\end{array}$ & $\begin{array}{c}12.9 \\
(7 ; 43.9)\end{array}$ & $\begin{array}{c}12.55 \\
(10.8 ; 14.3)\end{array}$ & $\begin{array}{c}12.65 \\
(7.2 ; 38.1)\end{array}$ & $\begin{array}{l}20.3 \\
(5.5 \\
39.5)\end{array}$ & $\begin{array}{c}27.4 \\
(12.5 ; 63)\end{array}$ & $\begin{array}{l}16.9 \\
(6.9 ; \\
33.5)\end{array}$ & $\begin{array}{c}20.2 \\
(3.7 ; 28.1)\end{array}$ & $\begin{array}{l}17.7 \\
(4.8 \\
45.8)\end{array}$ & $\begin{array}{l}15.4 \\
(8.6 ; \\
30.9)\end{array}$ & nd & $\begin{array}{c}61.3 \\
(25.17 ; 84 . \\
82)\end{array}$ & $\mathrm{p}=0.0001^{*}$ \\
\hline $\begin{array}{c}\text { RII } \\
\text { Amplitude, } \\
\text { nV }\end{array}$ & $\begin{array}{c}4.4 \\
(2.3 ; 10.1)\end{array}$ & $\begin{array}{c}9.1 \\
(6.6 ; 21.4)\end{array}$ & $\begin{array}{c}7.8 \\
(3.9 ; 25.5)\end{array}$ & $\begin{array}{c}6 \\
(2.3 ; \\
21.6)\end{array}$ & $\begin{array}{l}15.4 \\
(5.5 \\
39.4)\end{array}$ & $\begin{array}{c}7.4 \\
(1.9 \\
17.3)\end{array}$ & $\begin{array}{c}5.35 \\
(1.6 ; 15.4)\end{array}$ & $\begin{array}{c}6.4 \\
(1.1 \\
21.6)\end{array}$ & $\begin{array}{c}9.1 \\
(6.6 \\
39.4)\end{array}$ & nd & $\begin{array}{l}23.25 \\
(11.2 ; \\
36.07)\end{array}$ & $\mathrm{p}=0.0001^{*}$ \\
\hline $\begin{array}{c}\text { RIII } \\
\text { Amplitude, } \\
\text { nV }\end{array}$ & $\begin{array}{c}6.1 \\
(2.3 ; 10.1)\end{array}$ & $\begin{array}{c}4.5 \\
(2.3 ; 5.7)\end{array}$ & $\begin{array}{c}8.4 \\
(3.1 ; 23.7)\end{array}$ & $\begin{array}{l}2.85 \\
(0.7 \\
15.4)\end{array}$ & $\begin{array}{l}14.8 \\
(9.1 ; \\
25.6)\end{array}$ & $\begin{array}{c}5.7 \\
(1.2 \\
18.5)\end{array}$ & $\begin{array}{c}2.4(0.1 ; \\
12.8)\end{array}$ & $\begin{array}{l}2.9 \\
(0.8 \\
10.6)\end{array}$ & $\begin{array}{c}6.45 \\
(2.2 ; 9.2)\end{array}$ & nd & $\begin{array}{c}15.65 \\
(8.3 ; 22.4)\end{array}$ & $\mathrm{p}=0.0001^{*}$ \\
\hline $\begin{array}{l}\text { RIV } \\
\text { Amplitude, } \\
\text { nV }\end{array}$ & $\begin{array}{c}1.4 \\
(1.1 ; 1.5)\end{array}$ & $\begin{array}{c}1.4 \\
(0.9 ; 2)\end{array}$ & $\begin{array}{c}8.95 \\
(2.6 ; 22.8)\end{array}$ & $\begin{array}{l}2.1 \\
(0.4 \\
10.7)\end{array}$ & $\begin{array}{c}11.7 \\
(8.1 ; 19.3)\end{array}$ & $\begin{array}{l}2.95 \\
(1.1 ; \\
18.3)\end{array}$ & $\begin{array}{c}2.15 \\
(0.9 ; 11.8)\end{array}$ & $\begin{array}{c}2.6 \\
(1.2 ; 5.7)\end{array}$ & $\begin{array}{c}6.85 \\
(2.5 ; 7.6)\end{array}$ & nd & $\begin{array}{c}11.65 \\
(5.3 ; 16.3)\end{array}$ & $\mathrm{p}=0.0001^{*}$ \\
\hline $\begin{array}{c}\text { RV } \\
\text { Amplitude, } \\
\text { nV }\end{array}$ & $\begin{array}{c}1.4 \\
(1.3 ; 1.6)\end{array}$ & nd & $\begin{array}{c}10.5 \\
(4.7 ; 14.03)\end{array}$ & $\begin{array}{c}2.4 \\
(0.5 ; 10.8)\end{array}$ & $\begin{array}{c}12.1 \\
(7.4 ; 18.8)\end{array}$ & $\begin{array}{c}3.3 \\
(1.3 ; 9.2)\end{array}$ & $\begin{array}{c}2.1 \\
(1.5 ; 11.4)\end{array}$ & $\begin{array}{c}2.1 \\
(0.9 \\
10.15)\end{array}$ & $\begin{array}{c}7.65 \\
(3.4 ; 9.2)\end{array}$ & nd & $\begin{array}{c}10.35 \\
(4.7 \\
14.03)\end{array}$ & $\mathrm{p}=0.0001^{*}$ \\
\hline $\begin{array}{l}\text { RI Implicit } \\
\text { time, ms }\end{array}$ & $\begin{array}{l}28.3 \\
(26.6 ; \\
29.9)\end{array}$ & $\begin{array}{c}27.5 \\
(27.4 ; 29.2)\end{array}$ & $\begin{array}{c}31.5 \\
(24.9 ; 40)\end{array}$ & $\begin{array}{l}30.8 \\
(20.8 ; \\
36.7)\end{array}$ & $\begin{array}{c}30 \\
(26.7 ; \\
35.8)\end{array}$ & $\begin{array}{c}31.25 \\
(25.8 ; 40)\end{array}$ & $\begin{array}{c}30(25.7 \\
35)\end{array}$ & $\begin{array}{l}33.75 \\
(28.3 ; \\
42.3)\end{array}$ & $\begin{array}{l}33.3 \\
(33.2 ; \\
37.5)\end{array}$ & nd & $\begin{array}{l}29.2 \\
(25.8 ; \\
34.16)\end{array}$ & $\mathrm{p}=0.0032^{*}$ \\
\hline $\begin{array}{l}\text { RII Implicit } \\
\text { time, ms }\end{array}$ & $\begin{array}{l}29.1 \\
(28.3 ; \\
33.2)\end{array}$ & $\begin{array}{c}29.2 \\
(26.6 ; 31.6)\end{array}$ & $\begin{array}{c}30.8 \\
(28.2 ; 44.1)\end{array}$ & $\begin{array}{c}30.7 \\
(19.2 ; \\
37.5)\end{array}$ & $\begin{array}{c}30 \\
(15.4 ; \\
33.3)\end{array}$ & $\begin{array}{c}30.7 \\
(25 ; 44.1)\end{array}$ & $\begin{array}{l}32.9 \\
(27.4 . \\
41.1)\end{array}$ & $\begin{array}{c}32.85 \\
(24.2 ; 44)\end{array}$ & $\begin{array}{l}34.55 \\
(32.4 ; \\
39.1)\end{array}$ & nd & $\begin{array}{l}29.2 \\
(26.7 \text {; } \\
39.2)\end{array}$ & $\mathrm{p}=0.0382 *$ \\
\hline $\begin{array}{l}\text { RIII Implicit } \\
\text { time, ms }\end{array}$ & $\begin{array}{l}39.1 \\
(32.5 ; \\
52.5)\end{array}$ & $\begin{array}{c}29.1 \\
(26.6 ; 30.8)\end{array}$ & $\begin{array}{l}29.95 \\
(28.2 ; \\
47.08)\end{array}$ & $\begin{array}{l}30.8 \\
(27.5 ; \\
41.5)\end{array}$ & $\begin{array}{l}29.2 \\
(11.4 ; \\
31.7)\end{array}$ & $\begin{array}{c}32.4 \\
(25 ; 40.8)\end{array}$ & $\begin{array}{c}35.3(0.8 \\
63.2)\end{array}$ & $\begin{array}{l}32.85 \\
(28.3 ; \\
37.4)\end{array}$ & $\begin{array}{l}34.55 \\
(32.4 ; \\
36.7)\end{array}$ & nd & $\begin{array}{l}28.75 \\
(26.7 ; \\
32.41)\end{array}$ & $\mathrm{p}=0.0001^{*}$ \\
\hline $\begin{array}{l}\text { RIV Implicit } \\
\text { time, ms }\end{array}$ & $\begin{array}{l}40.8 \\
(33.3 ; \\
48.3)\end{array}$ & $\begin{array}{c}30 \\
(26.6 ; 35.8)\end{array}$ & $\begin{array}{c}30.4 \\
(28.2 ; \\
46.72)\end{array}$ & $\begin{array}{c}32.1 \\
(28.3 ; 44)\end{array}$ & $\begin{array}{c}30 \\
(9.1 \\
31.7)\end{array}$ & $\begin{array}{c}32.1 \\
(28.3 ; 44)\end{array}$ & $\begin{array}{c}37.45 \\
(30 ; 60.7)\end{array}$ & $\begin{array}{l}32.85 \\
(28.3 ; \\
36.7)\end{array}$ & $\begin{array}{c}34.55 \\
(33.2 ; 35)\end{array}$ & nd & $\begin{array}{l}28.3 \\
(25.8 ; \\
32.4)\end{array}$ & $\mathrm{p}=0.0001^{*}$ \\
\hline $\begin{array}{l}\text { RV Implicit } \\
\text { time, ms }\end{array}$ & $\begin{array}{l}40.8 \\
(37.7 ; \\
48.3)\end{array}$ & nd & $\begin{array}{l}30.35 \\
(29.1 \text {; } \\
43.85)\end{array}$ & $\begin{array}{l}32.9 \\
(26.7 \text {; } \\
46.6)\end{array}$ & $\begin{array}{c}30 \\
(8.5 ; 33.2)\end{array}$ & $\begin{array}{l}32.9 \\
(26.7 ; \\
46.6)\end{array}$ & $\begin{array}{l}37.45 \\
(30.8 ; \\
69.1)\end{array}$ & $\begin{array}{l}35.8 \\
(29.9 ; \\
41.6)\end{array}$ & $\begin{array}{l}32.9 \\
(28.2 \\
34.2)\end{array}$ & nd & $\begin{array}{l}28.3 \\
(26.7 \\
33 ; 2)\end{array}$ & $\mathrm{p}=0.0001^{*}$ \\
\hline
\end{tabular}

nd- not detectable; ${ }^{*}$-indicates that the difference was found to be statistically significant; $5^{\text {th }}$ and $95^{\text {th }}$ quantiles are indicated in parentheses; Kruskal-Wallis test $\left(\right.$ Chi ${ }^{2}$-test for more than 2 groups) was used for the comparison of IRD subgroups and subjects with normal ophthalmological finding.

in each of the IRD diagnoses, and the range of most probable diagnosis will be identified. Qualitative characteristics will be used to characterize parameters as normal, moderately reduced, severely reduced or not detectable in the case of amplitude, and normal, moderately prolonged, severally prolonged in the case of implicit time. This semiautomatic algorithm will help to communicate results to patients and other medical specialists and will make diagnosis of IRD more time efficient.

\section{CONCLUSIONS}

We conclude that a combined approach to the early identification and differential diagnosis of IRD is most appropriate when dealing with IRD patients. Despite the high importance of electrophysiological testing in the early differential diagnosis, it is obvious that the knowledge of the pattern of onset of the key diagnostic symptoms and signs is also important for clinicians and patients for early identification of IRD. In this study we discussed the main characteristics of specific electrophysiological signs for a variety of rare IRD that, along with knowledge of pattern of disease onset, will be very helpful for ophthalmologists, general practitioners, and researchers dealing with IRD patients. This also can help to formulate strict inclusion criteria for IRD patients in future and ongoing clinical trials.

\section{CONFLICT OF INTEREST}

The authors confirm that this article content has no conflicts of interest.

\section{ACKNOWLEDGEMENTS}

This research was undertaken at the Institute for Ophthalmic Research, Centre for Ophthalmology, University of Tuebingen, Germany. We would like to thank the team of senior resident ophthalmologists who examined the patients in the special clinic for IRD at the University Eye Hospital in Tuebingen. This study was supported by a stipend from the Tistou und Charlotte Kerstan Stiftung Vision 2000.

\section{REFERENCES}

[1] Stone EM. Progress toward effective treatments for human photoreceptor degenerations. Curr Opin Genet Dev 2009; 19: 2839 . 
[2] Revere KE, Chung DC. Recent breakthroughs in gene therapy for inherited retinal degeneration. Discov Med 2009; 8: 125-9.

[3] Gekeler F, Zrenner E. Status of the subretinal implant project: an overview. Ophthalmologe 2005; 102: 941-9.

[4] Prokofyeva E, Troeger E, Wilke R, Zrenner E. Early visual symptom patterns in inherited retinal dystrophies. Ophthalmologica 2011; 226: 151-6.

[5] Prokofyeva E, Troeger E, Bernd A, Zrenner E. Visual acuity changes in cone and cone-rod dystrophies. Ophthalmic Physiol Opt 2012; 32: 53-9.

[6] Prokofyeva E, Wilke R, Lotz G, Troeger E, Strasser T, Zrenner E. An epidemiological approach for the estimation of disease onset in central europe in central and peripheral monogenic retinal dystrophies. Graefes Arch Clin Exp Ophthalmol 2009; 247: 88594.

[7] Corbett MC, Shilling JS, Holder GE. The assessment of clinical investigations: the greenwich grading system and its application to electrodiagnostic testing in ophthalmology. Eye (Lond) 1995; 9 ( Pt $6 \mathrm{Su}): 59-64$.

[8] Berson EL. Electroretinographic findings in retinitis pigmentosa. Jpn J Ophthalmol 1987; 31: 327-48.

[9] Iannaccone A, Rispoli E, Vingolo EM, et al. Correlation between goldmann perimetry and maximal electroretinogram response in retinitis pigmentosa. Doc Ophthalmol 1995; 90: 129-42.

[10] Holopigian K, Greenstein V, Seiple W, Carr RE. Rates of change differ among measures of visual function in patients with retinitis pigmentosa. Ophthalmology 1996; 103: 398-405.

[11] Berson EL, Rosner B, Sandberg MA, et al. A randomized trial of vitamin a and vitamin e supplementation for retinitis pigmentosa. Arch Ophthalmol 1993; 111: 761-72.

[12] Hood DC. Assessing retinal function with the multifocal technique. Prog Retin Eye Res 2000; 19: 607-46.

[13] Langrova H, Zrenner E, Kurtenbach A, Seeliger MW. Age-related changes in retinal functional topography. Invest Ophthalmol Vis Sci 2008; 49: 5024-32.

[14] Seeliger MW, Zrenner E, Apfelstedt-Sylla E, Jaissle GB. Identification of usher syndrome subtypes by erg implicit time. Invest Ophthalmol Vis Sci 2001; 42: 3066-71.

[15] Iijima H, Yamaguchi S, Hosaka O. Photopic electroretinogram implicit time in retinitis pigmentosa. Jpn J Ophthalmol 1993; 37: 130-5.

[16] Scholl HP, Langrova H, Pusch CM, Wissinger B, Zrenner E, Apfelstedt-Sylla E. Slow and fast rod erg pathways in patients with $\mathrm{x}$-linked complete stationary night blindness carrying mutations in the nyx gene. Invest Ophthalmol Vis Sci 2001; 42: 2728-36.

[17] Nagy D, Schonfisch B, Zrenner E, Jagle H. Long-term follow-up of retinitis pigmentosa patients with multifocal electroretinography. Invest Ophthalmol Vis Sci 2008; 49: 4664-71.
[18] McGill R, Tukey JW, Larse WA. Variations of boxplots. Am Stat 1978; 32: 12-6.

[19] Kruskal WH, Wallis WA. Use of ranks in one-criterion variance analysis. J Am Stat Assoc 1952; 47: 583-621.

[20] Maritz JS, Jarrett RG. A note on estimating the varience of the sample median. J Am Stat Assoc 1978; 73: 194-6.

[21] Lyons JS, Severns ML. Using multifocal erg ring ratios to detect and follow plaquenil retinal toxicity: a review : review of mferg ring ratios in plaquenil toxicity. Doc Ophthalmol 2009; 118: 29-36.

[22] Marmor MF, Zrenner E. Standard for clinical electroretinography (1999 update). International society for clinical electrophysiology of vision. Doc Ophthalmol 1998; 97: 143-56.

[23] Sutter EE, Tran D. The field topography of erg components in man--i. The photopic luminance response. Vision Res 1992; 32: 433-46.

[24] Tröger E, Wilke R, Prokofyeva E, Zrenner E. Ophthabase: a generic extensible patient registry system. Acta Ophthalmol 2008; 86.

[25] Tröger E, Prokofyeva E, Wilke R, Zrenner E. Reusability in patient registries-implamention of generic extensible web-based patient registry system. In: Azevedo LLA, Ed. Second International Conference on Health Informatics, HEALTHINF 2009. Porto, Portugal: INSTICC Press 2009; pp. 438-41.

[26] Scholl HPN. Photoreceptor type-specific electroretinorgapy in inherited retinal disorders. Norderstedt: Books on Demand GmbH 2004.

[27] Langrova H, Zrenner E, Kurtenbach A, Seeliger MW. Age-related changes in retinal functional topography. Invest Ophthalmol Vis Sci 2008; 49: 5024-32.

[28] van Lith G. Subnormal and absent ergs: What do we mean with this terms? Doc Ophthalmol Proc Ser 1982; 31: 13-7.

[29] Fishman GA, Birch DG, Holder GE, Brigel MG. Electrophisiology testing in disorders of retina, optic nerve, and visual pathways. Singapore: The Foundation of the American Avademy of Ophthalmology 2001.

[30] Fishman GA, Alexander KR, Anderson RJ. Autosomal dominant retinitis pigmentosa: a method of classification. Arch Ophthalmol 1985; 103: 366-74.

[31] Lam B. Electrophysiology of vision: clinical testing and applications. Boca Raton, FL: Taylor and Francis Group 2005.

[32] Lois N, Holder GE, Bunce C, Fitzke FW, Bird AC. Phenotypic subtypes of stargardt macular dystrophy-fundus flavimaculatus. Arch Ophthalmol 2001; 119: 359-69.

[33] Yanagihashi S, Nakazawa M, Kurotaki J, Sato M, Miyagawa Y, Ohguro H. Autosomal dominant central areolar choroidal dystrophy and a novel arg195leu mutation in the peripherin/rds gene. Arch Ophthalmol 2003; 121: 1458-61.

[34] Carr RE. Central areolar choroidal dystrophy. Arch Ophthalmol $1965 ; 73: 32-5$. 